\title{
Effect of Mode of Delivery on Sexuality of Female and Her Partner \\ N.A.Said, SH.H.Ahmed, A.A.El-wahab
}

Dermatology, Venereology \& Andrology Dept., Benha Univ., Benha, Egypt.

E-Mail: ena_mahed@yahoo.com

\begin{abstract}
Exploring the hypothesis that "sexual function" is related to mode of delivery is necessary as sexual health is considered as an integral part of general health. The over risks and benefits of vaginal versus cesarean delivery should be a subject of continued debate, involving a broad range of physical and psychological factors. The aim of this study was to quantify the effect of mode of delivery on sexual function of the women 6 months to 1 year postpartum in a sample of Egyptian women. This was a cross section study conducted on 400 participants, 200 who had normal vaginal delivery [NVD] and 200 who had caesarian section [CS]. Participants were enrolled from the primary health centers and units in Qalubia government, participant were asked to fill a self-reported questionnaire of female sexual function index [FSFI].the results showed that all sexual domains and total FSFI were significantly decreased in normal vaginal group [NVD] group compared to caesarian section[CS] group .In conclusion, significant decrease in the FSFI score in NVD group more than CS group, this need more and more studies to strength this result.
\end{abstract}

Key Words: Mode of delivery, Normal vaginal delivery, Caesarian section, FSFI.

\section{Introduction}

Sexual dysfunction or sexual malfunction is difficulty experienced by an individual or a couple during any stage of a normal sexual activity. According to the DSM-V, sexual dysfunction requires a person to feel extreme distress and interpersonal strain for a minimum of 6 months [excluding substance or medication-induced sexual dysfunction] [1]. Sexual dysfunctions can have a profound impact on individual's perceived quality of sexual life [2].

Female sexual dysfunction [FSD] is defined as disorders of sexual desire, arousal, orgasm, and sexual pain, which lead to personal distress. The etiology of sexual dysfunction is frequently multifactorial as it is related to physical and mental wellbeing, quality of relationship, social class, education, employment, life stress, personal factors and partner's age and health [3].

The prevalence of female sexual dysfunction is largely unknown and likely to be under stood but it has been reported that approximately $40-45 \%$ of adult women suffer from sexual dysfunction [4]. Sexual dysfunction is more prevalent in women than in men [5].

Pregnancy and delivery affect multiple physiological, functional, and mental functions that interfere with sexuality. Endocrine and psychosomatic factors as well as anatomical changes during pregnancy and different forms of delivery may provoke female sexual dysfunction [6].

In the last decade there has been an increasing number of women who requesting elective cesarean delivery, despite that obstetric practice guidelines developed over the past decade aimed at reducing the cesarean delivery rate [7]

The major reasons for avoiding vaginal delivery were the fear of childbirth and the concern for postpartum sexual health. Such evidence might cause high preference rate of elective caesarean section due to the perceived benefits of this mode of birth [8].

The extent to which the mode of delivery contributes to sexual dysfunction is not clear, nor is the relationship between mode of delivery and pelvic muscle strength [9].

The over risks and benefits of vaginal versus cesarean delivery should be a subject of continued debate, involving a broad range of physical and psychological factors [10] Among the various reasons for this increased trends of CS delivery, the fear of genital modifications after VD, with their subsequent effects on postpartum coital activity, is one of the most commonly reported reasons for requesting CS. There is scanty, controversy published information evaluating the long term data on the relationship between the mode of delivery and sexual function.

\section{Subjects and methods}

This is a cross section observational study which was conducted on 400 married women 6 months to 1 year postpartum. This study obtained approvement from the department of Dermatology and Andrology and the research ethics committee in Benha faculty of medicine.

\subsection{Inclusion criteria}

All women should be sexually active [married and living with their husbands for at least 6 months prior to the study].

\subsection{Exclusion criteria}

- Women above 50 years old. .

- Women who take any hormonal treatment or contraception

- Women who had any disease that affects their sexual function as DM and hypertension

- Participants with psychiatric problem

\subsection{Methods}

The participants were enrolled from the primary health care centers and units in Qualiobia 
government. The present work aimed to compare between the effects of both normal vaginal delivery and cesarean section on female sexual function in a sample of Egyptians participants.

This study included 400 married women. They were divided equally into 2 groups: Group A: Comprised 200 women who had normal vaginal delivery and Group B: Comprised 200 women who had cesarean section.

All women were asked to fill out an Arabic validated version questionnaire of female sexual function index [FSFI] [11] .The FSFI is a validated 19-item, self $\quad$-administrated screening questionnaire that measures the aspects of sexual function of the women [desire, arousal, lubrication, orgasm and pain].

\subsection{Statistical Design}

The collected data was tabulated and presented in suitable figures and tables. Quantitative data was summarized using mean and standard deviation, while, qualitative data was analyzed using frequency and percentage. Data was analyzed by the aid of software package of SPSS using suitable statistical tests. The accepted level of significance in this work was $0.05[p<0.05$ will be considered significant].

\section{Results}

The most common age group of participants was 20-29 years, the most common education level is high to moderate level and most of participants were living in urban areas Table (1). All sexual domains and total FSFI were significantly decreased in normal vaginal delivery group $[p<0$. 05] compared to cesarean section group Table(2).Female sexual dysfunction was detected statistical significant in multiparous female in both groups compared to nulliparous female Table (3]. The mean of all sexual domains were insignificantly lowered $[p>0.05]$ in those with vaginal looseness compared to their counterparts with no vaginal looseness with a significant difference only in two domains [arousal $=0.009$ \&lubrication $=0.051]$ Table $(4)$.

Table (1) demographic data

\begin{tabular}{|c|c|c|c|c|c|c|}
\hline & \multicolumn{2}{|c|}{$\overline{C S}$} & \multicolumn{2}{|c|}{ NVD } & \multirow[t]{2}{*}{$\mathrm{X}^{2}$ Test } & \multirow[t]{2}{*}{$P$ value } \\
\hline & No & $\%$ & No & $\%$ & & \\
\hline \multicolumn{7}{|l|}{$\overline{\text { Age }}$} \\
\hline$<20 y s$ & 19 & 9.5 & 11 & 5.5 & 5.05 & 0.08 \\
\hline 20-30ys & 153 & 76.5 & 147 & 73.5 & & \\
\hline$>30 y s$ & 28 & 14.0 & 42 & 21.0 & & \\
\hline Mean \pm SD & \multicolumn{2}{|c|}{$36.22 \pm 5.4$} & \multicolumn{2}{|c|}{$37.14 \pm 6.62$} & St $\mathrm{t}=1.52$ & 0.06 \\
\hline Range & \multicolumn{2}{|c|}{$17-51$} & \multicolumn{2}{|c|}{$19-50$} & & \\
\hline \multicolumn{7}{|l|}{ Level of education } \\
\hline University & 80 & 40.0 & 40 & 20.0 & 20.9 & $<0.001 * *$ \\
\hline Secondary & 77 & 38.5 & 115 & 57.5 & & \\
\hline Read and write & 43 & 21.5 & 45 & 22.5 & & \\
\hline \multicolumn{7}{|l|}{ Resident } \\
\hline Urban & 160 & 80.0 & 191 & 95.5 & 22.35 & $<0.001 * *$ \\
\hline Rural & 40 & 20.0 & 9 & 4.5 & & \\
\hline
\end{tabular}

Table (2) FSFI score and mode of delivery

\begin{tabular}{|c|c|c|c|c|c|c|c|c|}
\hline \multirow{2}{*}{$\begin{array}{l}\text { FSFI } \\
\text { domains }\end{array}$} & \multicolumn{3}{|c|}{$\mathrm{CS}$} & \multicolumn{3}{|c|}{ NVD } & \multirow[t]{2}{*}{ St t test } & \multirow[t]{2}{*}{$P$ value } \\
\hline & Mean & SD & Range & Mean & SD & Range & & \\
\hline Desire & 4.0 & 1.10 & $1.2-6$ & 3.53 & 0.93 & $1.2-6$ & 4.65 & $<0.001 * *$ \\
\hline Arousal & 4.39 & 0.92 & $1.2-6$ & 4.10 & 1.14 & $1.2-6$ & 2.76 & $0.006 * *$ \\
\hline Lubrication & 4.65 & 1.0 & $1.2-6$ & 4.25 & 1.14 & $1.2-6$ & 3.75 & $<0.001 * *$ \\
\hline Orgasm & 4.43 & 0.87 & $1.2-6$ & 4.34 & 1.05 & $1.2-6$ & 0.89 & 0.37 \\
\hline Satisfaction & 5.06 & 0.98 & $1.2-6$ & 4.85 & 0.95 & $1.2-6$ & 2.22 & $0.027 *$ \\
\hline Pain & 4.14 & 1.27 & $1.2-6$ & 3.79 & 1.29 & $1.2-6$ & 2.75 & $0.006 * *$ \\
\hline Total FSFI & 26.67 & 4.14 & $7.2-36$ & 24.85 & 4.30 & $\begin{array}{l}14.2- \\
34.2\end{array}$ & 4.30 & $<0.001 * *$ \\
\hline
\end{tabular}

Table (3) parity and FSD

\begin{tabular}{lllll}
\hline Female sexual & CS $[n=200]$ & NVD $[n=200]$ & F test & P value \\
\hline
\end{tabular}




\begin{tabular}{lcccccl}
\hline dysfunction[ $\leq$ & NP & MP & NP & MP & & \\
26.55] & No [\%] & No [\%] & No [\%] & No [\%] & & \\
\hline Present & $30[30 \%]$ & $51[51.0 \%]$ & $57[57 \%]$ & $68[68 \%]$ & \multirow{2}{*}{30.63} & $<0.001 * *$ \\
Absent & $70[70 \%]$ & $49[49.0 \%]$ & $43[43 \%]$ & $32[32 \%]$ & & \\
\hline
\end{tabular}

Table (4) vaginal looseness and FSD

\begin{tabular}{|c|c|c|c|c|c|c|}
\hline \multirow{2}{*}{$\begin{array}{l}\text { Vaginal loosenes } \\
\text { Female scores }\end{array}$} & \multicolumn{2}{|c|}{ [YES [112 } & \multicolumn{2}{|c|}{ [NO [69 } & \multirow[t]{2}{*}{ St t } & \multirow[t]{2}{*}{ P value } \\
\hline & Mean & \pm SD & Mean & \pm SD & & \\
\hline Desire & 3.61 & 0.96 & 3.41 & 0.92 & 1.4 & 0.16 \\
\hline Arousal & 3.96 & 1.12 & 4.42 & 1.12 & 2.65 & $0.009 * *$ \\
\hline Lubrication & 4.2 & 1.11 & 4.53 & 1.07 & 1.97 & $0.051 *$ \\
\hline Orgasm & 4.3 & 0.98 & 4.47 & 1.16 & 1.08 & 0.28 \\
\hline Satisfaction & 4.76 & 0.90 & 4.98 & 0.96 & 1.52 & 0.13 \\
\hline Pain & 3.73 & 1.20 & 3.90 & 1.49 & 0.84 & 0.40 \\
\hline Total FSFI & 24.57 & 4.24 & 25.71 & 4.43 & 1.73 & 0.09 \\
\hline
\end{tabular}

\section{Discussion}

Attitudes to sexuality changed dramatically during the $20^{\text {th }}$ century. Sexual dysfunction [SD] in men and women is a fairly common problem worldwide [12]. Sexual health is perceived as an integral part of general health as it can markedly affect quality of life [QOL]; hence, nowadays more attention is given to the sexual health.

Pregnancy and delivery affect multiple physiological, functional, and mental functions that interfere with sexuality. Endocrine and psychosomatic factors as well as anatomical changes during pregnancy and different forms of delivery may provoke female sexual dysfunction [6]. In the last decade there have been an increasing number of women requesting elective cesarean delivery, despite that obstetric practice guidelines developed over the past decade aimed at reducing the cesarean delivery rate [7]. Also, there has been a change in attitude by obstetricians toward cesarean section [CS] [13].

Although this remarkable trend may reflect an increase in the prevalence of CS indications, it was reported that the majority of CS deliveries in developing countries are performed without a clear indication and are not associated with clinically detected benefits on the mothers and newborns [14].

Among the various reasons for this increased trends of CS delivery, the fear of genital modifications after VD, with their subsequent effects on postpartum coital activities. There has been a debate about the appropriateness of CS performed due to maternal request or what pphysicians suggest to their patients [15].

[16-17] studies stated that mode of delivery and childbirth experience may have a long-term effect on self-rated health.

This study tried to explore different aspects of the relationship between mode of delivery and female sexuality in a sample of Egyptian couples.
In the present study, all sexual domains and total score of FSFI were significantly decreased in female with vaginal delivery group compared to those in caesarian section group and this was in agreement with [18] study.

Although there are plausible studies that could argue for the improved sexual function among women with cesarean section, major gaps in information about sexual functioning still needs more research.

The deterioration of female sexual function after NVD was explained by [10-19] as they stated that NVD is a potent determinant of stress urinary incontinence [SUI], NVD carry's more than twice the risk of SUI. Moreover, [20] study stated that specific risk factors for SUI are correlated with reduced sexual function.

The results of the current study dis agree with the previous study [19], these difference was also due to different time in which every study was done after delivery, where they enrolled their participant in the first 3 to 6 months postpartum while we enrolled them 6 months to 1 year postpartum ,the effect of time after delivery on sexual function was also suggested by [21] study .

In addition, [22] reported that women who had NVD even one child have a risk of a pelvic floor disorder higher than a woman who had many children by CS .

According to the results of the current study the number of MP participant in both groups had SD more than NP, and this was in agreement with [23] study which justified this result to higher level of energy and less fatigue observed in women with few children

On other hand, [24] in their USA study reported that parity was not statistically significantly associated with any type of sexual difficulties.

The present study demonstrated that $56 \%$ of the females who had vaginal delivery complained of vaginal looseness. This was in partial agreement with a survey done by [25] study which included of 25 to 45-year-old women with at least one 
vaginal birth, reported that approximately half of women expressed concern over vaginal looseness. In addition, [26] study also reported that vaginal looseness was the most common physical concern discussed with obstetric-gynecologists [OBGYNs] after vaginal childbirth.

The current study showed that $62.5 \%$ female participant who had NVD had some form of FSD from which $58.4 \%$ had vaginal looseness or were circumscribed, Arousal and the lubrication domains were the most sexual domains which are affected with significant difference in our study. This was also detected in study [27], they reported that there was some form of sexual dysfunction present in about $58 \%$ of mothers one year after vaginal delivery, their main complaints included insufficient lubrication, abnormal vaginal sensation, vaginal laxity, vaginal tightness, pain with intercourse and incontinence during intercourse. So vaginal looseness appears to be a rather common complaint, or at the very least, a meaningful concern for many women following vaginal birth.

In the present study there was in significant correlation between age of females and FSFI. This was in contrary to the findings of [22] study. They found that age was a significant factor in experiencing sexual problems and that the risk for experiencing sexual problems was increased as the age of women increased this may be due to higher level of energy and less fatigue in younger women. This discrepancy could be explained as the majority of our participants females were from 20 to 30 years old.

\section{Conclusion}

In our study we included that NVD affected more on the sexuality of the female .

\section{References}

[1] S.Nolen-Hoeksema, Now updated to reflect the DSM-5. In Abnormal Psychology. McGraw-Hill Humanities. 6th.ed, Vol.23,PP.366-367,2014.

[2] K.J. Eden and KR.Wylie , Quality of sexual life and menopause. Women's Health.5 [4], NIH Conference NIH consensus development panel on impotence.Impotence. J.A.M.A, Vol.270,PP.83-90.385-396,2008.

[3] E. E.Aslan and M.Fynes, Female Sexual Dysfunction Int J. P,Vol.19(2),PP.293 305,2009.

[4] R.W.Lewis , K.Fugl-Meyer and R.Bosch , Epidemiology and risk factors of sexual dysfunction. J Sex Med, Vol.1(3),PP.3539,2004.

[5] A.M. Elnashar, M.Ibrahim ,M.M. El-Desoky ,O. Ali , Female Sexual Dysfunction in Lower Egypt. B.J.O.G.114,Vol.2.PP.201206,2007.

[6] A.O.Yeniel and E.Petri. Prgnancy, childbirth and sexual function : Perception and facts .Int Urogynecol J ,Vol.25,PP.540,2014.

[7] Centers for disease control and prevention [CDC] Vaginal birth after cesarean birth -
California,. MMWR Morb Mortal Wkly Rep,Vol.51,PP.996-998,2002.

[8] S.E.Althof, S.R. Leiblum, M. ChevretMeasson, U. Hartmann, S.B. Levine, M.McCabe, M. Plaut, O.Rodrigues and K.Wylie, Psychological and interpersonal dimensions of sexual function and dysfunction. J Sex Med,Vol.2,PP.793800,2005 .

[9] M.F. Goetsch, Postpartum dyspareunia: An unexplored problem. J Reprod Med, Vol.44,PP.963-968,1999.

[10] R.P.Goldberg, Y.Abramov , S.Botros , Delivery mode is a major environmental determinant of stress urinary incontinence: results of the Evanston-Northwestern Twin Sisters Study. Am J Obstet Gynecol, Vol.193,PP.2149-53,2005.

[11] T.H.Anise , S.A.Gheit , H.S.Saied , and S.A.A.l kherbash,Arabic translation of female sexual function index and validation in an Egyptian population.J. Sex. Med,Vol.8[12],PP.3370-3378,2011.

[12] M.R. Safarinejad, Female sexual dysfunction in a population- based study in Iran: Prevalence and associated risk factors. Int $\mathbf{J}$ Impot Res,Vol.18,PP.382-95,2006.

[13] L.Impey and P.Boylan, Active management of labour revisited.Br J Obstet Gynaecol, Vol.106,PP.183-7,1999.

[14] World Health organization. WHO statment on caesarean section rates. Reproductive Health Matters. Geneva: WHO, Vol. 2015,PP.149-150,2015.

[15] Y.S. Chong , K.Y.Kwek ,Safer childbirth. Avoiding medical interventions for nonmedical reasons. Lancet,Vol.375,pp4402,2010.

[16]E. Schytt ,U. Waldenström, Risk factors for poor self-rated health in women at 2 months and 1 year after childbirth. J Womens Health [Larchmt],Vol.16,PP.390-405,2007.

[17] J.C.Eisenach ， P.H.Pan ， R.Smiley , P.Lavand,homme, R. Landau, Severity of acute pain after childbirth, but not type of delivery, predicts persistent pain and postpartum depression. Pain, Vol.140,PP.8794,2008.

[18]B.Baksu ,I. Davas ,E. Agar ,A. Akyol and A. Varolan, The effect of mode of delivery on postpartum sexual functioning in primiparous women. Int Urogynecol J Pelvic Floor Dysfunct, Vol.18,PP.401-6,2007.

[19]S. Gungor , I.Baser , T.Ceyhan , E.Karasahin, and S.Kilic,Does mode of delivery affect sexual functioning of the man partner? J Sex Med ,Vol.5,PP.155163,2008 .

[20] S.H.Yang ， J.M.Yang, K.H.Wang KH, Biologic cooelates of sexual function in women with stress urinary incontinence. J Sex Med,Vol.5,PP.2871-9,2008.

[21] S.R.Chang,T.C.Chang,K.H. Chen, Sexual function in women 3 days and 6 weeks after childbirth: A prospective longitudinal study 
using the Taiwan version of the Female Sexual Function Index. J Sex Med,Vol.7,PP.3946-3956,2010.

[22] E.S.Lukacz, J.M.Lawrence, R.Contreras, Parity, mode of delivery, and pelvic floor disorders. Obstet Gynecol,Vol.107,PP.125360,2006

[23] S.R.Chang, T.C.Chang, K.H. Chen, Sexual function in women 3 days and 6 weeks after childbirth: A prospective longitudinal study using the Taiwan version of the Female Sexual Function Index. J Sex Med, Vol.7,PP.3946-3956,2010.

[24] M.A.Shirvani, M.B. Nesami and M.Bavand. Maternal sexuality after child birth among Iranian women. Pak. J Biol Scien, Vol.13 [8],pp381- 389,2010.

[25] J.I.Shifren, B.U.Monzand, P.A. Russo, Sexual proplems and distress in United States women. Prevelance and correlation.
Obstet. Gynecol,Vol.112,PP.97097882,2008.

[26] L.Millheiser ，S. Kingsberg , R. Pauls, A cross-sectional survey to assess the prevalence andsymptoms associated with laxity of the vaginal introitus [abstract 206]. Presented at: ICS Annual Meeting; Toronto, Ontario, Canada, Vol.12,PP.23-27,2010.

[27]P.N. Pauls, A.N.Fellner , G.W.Davila. Vaginal laxity, a poorly understood quality of life problem; a survey of physician members of the International Urogynecological Association [IUGA]. Int Urogynecol J,Vol.23,PP.1435-1448, 2012.

[28] C.M. Durnea , A.S.Khashan , L.C.Kenny , S.S.Tabirca , B.Reilly, The role of prepregnancy pelvic floor dysfunction in postnatal pelvic morbidity in primiparous women. Int Urogynecol J,Vol.25,PP.136374. 2014. 